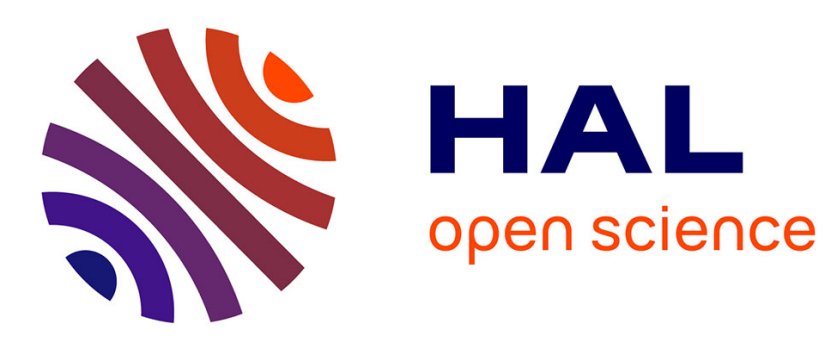

\title{
Imaging bacterial cells and biofilms adhering to hydrophobic organic compounds-water interfaces
}

Alexis Canette, Priscilla Branchu, Régis Grimaud, Murielle M. Naitali

\section{To cite this version:}

Alexis Canette, Priscilla Branchu, Régis Grimaud, Murielle M. Naitali. Imaging bacterial cells and biofilms adhering to hydrophobic organic compounds-water interfaces. McGenity, Terry J., Timmis, Kenneth N., Nogales Fernández, Balbina. Hydrocarbon and Lipid Microbiology Protocols, Springer, 2016, Springer Protocols Handbooks, 978-3-662-49135-5. 10.1007/8623_2015_80 . hal-01294116

\section{HAL Id: hal-01294116 https://hal.science/hal-01294116}

Submitted on 27 Mar 2016

HAL is a multi-disciplinary open access archive for the deposit and dissemination of scientific research documents, whether they are published or not. The documents may come from teaching and research institutions in France or abroad, or from public or private research centers.
L'archive ouverte pluridisciplinaire HAL, est destinée au dépôt et à la diffusion de documents scientifiques de niveau recherche, publiés ou non, émanant des établissements d'enseignement et de recherche français ou étrangers, des laboratoires publics ou privés. 
2 Imaging bacterial cellsand biofilms adhering to hydrophobic organic compounds-water interfaces

4 Authors

5 Alexis Canette, Priscilla Branchu, Régis Grimaud*, Murielle Naïtali

6 Affiliation

$7 \quad$ Alexis Canette

8 INRA, UMR 1319 Micalis, Domaine de Vilvert, 78350 Jouy-en-Josas, France

9 and

10 AgroParisTech, UMR Micalis, 1 avenue des Olympiades, 91300 Massy, France

11 alexis.canette@jouy.inra.fr

Priscilla Branchu

INRA, UMR 1319 Micalis, Domaine de Vilvert, 78350 Jouy-en-Josas, France and AgroParisTech, UMR Micalis, 1 avenue des Olympiades, 91300 Massy, France priscilla.branchu@ifr.ac.uk

Régis Grimaud *Corresponding author

Université de Pau et des Pays de l'Adour, Equipe Environnement et Microbiologie, UMRCNRS 5254 IPREM, IBEAS - BP1155, 64013 Pau Cedex, France. regis.grimaud@univ-pau.fr

Murielle Naïtali

INRA, UMR 1319 Micalis, Domaine de Vilvert, 78350 Jouy-en-Josas, France and AgroParisTech, UMR Micalis, 1 avenue des Olympiades, 91300 Massy, France murielle.naitali@agroparistech.fr 
Assimilation of Hydrophobic Organic Compound (HOC) entails frequently the formation of biofilm at the HOC-water interface.Knowledge on the behavior of cells at the oil-water interface and within the structured biofilm is therefore important to understand the degradation of the HOC in ecosystems. The adhesion and biofilm formation on oil-water interface is best documented by microscopic observations. In this chapter we thus describe two methods for observation of bacterial cells and biofilms growing at the HOC-water interface. The first method uses CLSM (confocal laser scanning microscopy) to obtain in situ images of biofilm developing on thin paraffin strip which offers a flat transparent surface allowing imaging directly through the bottom of the culture dish without sampling. Alternatively, the biofilm can be grown on a paraffin strip deposited on a glass microscope slide and then imaged from the top when high resolution is needed. The second method addresses the problematic of the ultrastructure of biofilm developing on HOC. It enables to obtain by TEM (transmission electron microscopy) images of cross sections of biofilms with identification of the side in contact with the HOC.

\section{Key Words}




\section{Introduction}

Hydrophobic Organic Compounds (HOC), includingthe chemical classes of lipids and hydrocarbons are ubiquitous components of the organic matter in ecosystems. The so called oleolytic bacteria have the ability to use members of either one or both classes as a substrate $(1,2)$.However, they have to face the very low water solubility of these substrates. Adhesion to the HOC-water interface and the subsequent formation of biofilms (3D-architectures of bacterial cells embedded within matrixes of biopolymers) are strategies shared by many oleolytic bacteria to overcome the low solubility of their substrates $(3,4,5)$. Different mechanisms have been proposed for the stimulation of the rate of mass transfer from the oily phase to cell surface. The localization of cell in the vicinity of the interface results in reduction of the length of the diffusion pathway of the hydrocarbon from the interface to the cell surface which in turn increases the mass transfer rate (6). Extracellar matrixes of biofilms provide confined environments where biosurfactants can be accumulated and contribute to hydrocarbons uptake by substrate emulsification or pseudo-solubilization. A direct contact of bacteria with hydrocarbons is also possible via the modification of the cell surface (7)offering the possibility of direct uptake from the hydrocarbon-water interface, although this remained to be demonstrated. In the case of lipids which must undergo hydrolysis into fatty acids by extracellular lipases before uptake by the cell, adhesionand biofilm formation at the water-lipidinterface provide the advantage to retain together the exo-enzymes, the lipids, the hydrolysis productsand the cells thus preventing them from rapid transportation to bulk water. The behavior of cells at the oil-water interface and within the structured biofilm is therefore one important aspect of the degradation of the HOCs in ecosystems.

The adhesion and biofilm formation at the oil-water interface is best studied by microscopic observations. Although a huge number of HOCs degrading strains have been isolated over the past decades, adhesion of these strains to their substrate is rarely documented. Only few authors provided images of bacteria cells adhered to HOC-water interfaceusing light microscopy, scanning electron microscopyand confocal laser scanning microscopy $(\operatorname{CLSM})(8,9,10,11,12,13)$. Studies of the behavior of bacteria at the HOC-water interface and within biofilms often involve examination and comparison of different strains (wild type versus mutants or different species).This can be only 
achieved if the HOC-water interfaces generated are compatible with the quantitative measurement of the adhesion or biofilm formation that is hardly the case with spherical or hemispherical droplets of HOC and crystals of irregular shape. To fulfill these requirements, we propose a methodology using thin films of paraffin $(15 \mu \mathrm{m})$ to generate a substratum togrow biofilms. Ultrathin paraffinfilmsare obtained by slicing solid paraffin with a microtome. Paraffin films pasted to the bottom of a culture dishoffer a flat surface and are thin enough to allow in situobservation through the bottom of the culture dish avoiding thus disruption of the biofilm structure. A better definition of imaging can be obtained using a microscope glass slide as solid substratum to paste the paraffin; the biofilm is then observed upside-down through a coverslip.

Determination of the ultrastructure of biofilms adhered to HOC-water interface are also of great interest. In general, biofilm cells exhibitheterogeneity in their physiology which can be reflected by the presence of different morphotypes. In the case of biofilm developing on hydrocarbons,intracellular inclusions of storage lipids have been often observed(14).For instance, biofilm cells of Marinobacter hydrocarbonoclasticusSP17 growing on hexadecane accumulate wax ester in their cytoplasm. These storage lipids persistafter detachment from the biofilm and provide cells with energy for colonization ofunoccupied interfaces (15). Lipid inclusions can be investigated using CLSM using specific fluorescent dye (figure 1). However, the ultrastructure of growing cells on HOCs is best studied using transmission electron microscopy $(\mathrm{TEM})(\mathbf{1}, \mathbf{1 6})$. The distribution and arrangement of cells containing inclusions within the biofilm can be investigated by TEMprovided that the biofilm structure is preserved and the orientation of the biofilm in respect to the HOC surface is traceable. Here, we describe a method where the biofilm is grown in a petri dish whose the bottom has been coated with paraffin. TEM requires sectioning the biofilm included in epoxy resin. As paraffin is incompatible with epoxy resin, the biofilm is removed from the paraffin surface by embedding it in agarose. Then agarose pieces are processed for TEM by paying attention to keep track of the side bearing the biofilm. This procedure enables to obtain images of cross sections of biofilms with identification of the side in contact with the paraffin. The imaging methods were both applied on a marine gram negative bacterium, Marinobacter hydrocarbonoclasticusSP17 and on a gram positive bacteriumRhodococcus equi NapRu1. 


\section{Materials}

\subsection{Observation of biofilms grown on paraffin by CLSM}

2.1.1 Strains, culture media and substratum for biofilm growth

107 108

1.The protocol described here has been developed with the bacterial strains $M$. hydrocarbonaclasticus SP17(17)and R.equiNapRu1 (3) (Note 1)

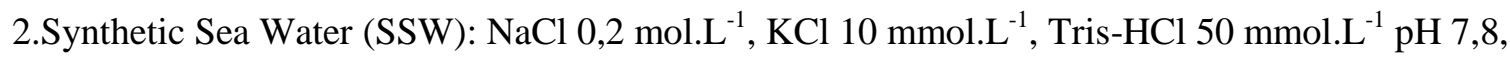
$\mathrm{NH}_{4} \mathrm{Cl} 56$ mmol.L $\mathrm{L}^{-1}, \mathrm{~K}_{2} \mathrm{HPO}_{4} 427 \mu$ mol.L ${ }^{-1}, \mathrm{FeSO}_{4} 8 \mu$ mol.L ${ }^{-1}, \mathrm{MgSO}_{4} 65$ mmol.L ${ }^{-1}$ et $\mathrm{CaCl}_{2}$ 13 mmol. $\left.\mathrm{L}^{-1}\right)($ Note 2$)$

3. Sodium lactate 2 mol. $\mathrm{L}^{-1}$ adjusted to $\mathrm{pH} 7$

4. Paraffin Normal Q Path® (VWR International, France)

5. Petri dishes (55 and $90 \mathrm{~mm}$ diameter) (Note 3)

6. Washed glass microscopic slides $(25 \times 75 \mathrm{~mm})$ (Note 4$)$

7. Ultramicrotome (UC6, Leica microsystems, Germany)

\subsubsection{CLSM observation of the biofilm}

1.Fluorescent dye: Syto®9 (L-10316, Life Technologies, France), Syto®61 (S-11343, Life Technologies), BODIPY® (D-3922, Life technologies) (Note 5)

2. Glass coverslips $N^{\circ} 1.5$ (Knittel Gläser, Germany)

3. Silicon spacer for coverslip, Press-to-Seal ${ }^{\mathrm{TM}}, 1 \mathrm{~mm}$ thick (Invitrogen ${ }^{\mathrm{TM}}$, Life Technologies)

4.Inverted Confocal Laser Scanning Microscope, Leica TCS SP8 AOBS (Leica Microsystems, Germany) (Note 6) 


\subsection{Observation of biofilms grown on paraffin by TEM}

128

129

130

131

132

2.2.1 Strains, culture media and substratum for biofilm growth

See subheading 2.1.1

2.2.2 TEM observation of the biofilm

1. Sodium cacodylate buffer 0.15 or 0.1 mol.L $\mathrm{L}^{-1}$, pH 7.4 (Sigma-Aldrich, France) (Note 8). The pH is adjusted with $\mathrm{HCl}$

2.Fixative solution (preparedextemporaneously): $2.5 \%$ glutaraldehyde (from glutaraldehyde solution Grade I, $25 \%$ in $\mathrm{H}_{2} \mathrm{O}$, Sigma-Aldrich) in $0.15 \mathrm{M}$ sodium cacodylate buffer at $\mathrm{pH} 7.4$ or $0.10 \mathrm{M}$ sodium cacodylate buffer at $\mathrm{pH} 7.4$ (Note 8)

3.Post-fixative solution (preparedextemporaneously): 1\% osmium tetroxide (Electron Microscopy Sciences, France) in $0.15 \mathrm{M}$ sodium cacodylate buffer at $\mathrm{pH} 7.4$ or $0.10 \mathrm{M}$ sodium cacodylate buffer pH 7.4 (accordingly to the fixative solution)

4.2.5\% agarose solution in distilled water (Seakem ${ }^{\circledR}$ LE agarose, Lonza, France).Agarose solution must be maintained at $50{ }^{\circ} \mathrm{Cinan}$ incubator for example(Note 9)

5.Ethanol 99.8\% (AnalaR NORMAPUR, VWR International)

6.Fresh or thawed epoxy resin (R1165, Low Viscosity Resin - Medium grade, Agar Scientific, France)

(Note 10)

7.A filtered solution of $0.05 \%$ oolong tea extract (OTE) in distillated water (OTE, Eloïse, France)

(Note 11)

9.Whatman ${ }^{\circledR}$ grade $\mathrm{n}^{\circ} 1$ cellulose filter paper (Sigma-Aldrich)

$10.2 \mathrm{~mL}$ Eppendorf®microcentrifuge tubes (Eppendorf, France) (Note 12) 
148 11.Rotator for Eppendorf microcentrifuge tubes

149 12.Vacuum desiccator

150 13.Diamond knife for ultrathin sectioning ( $35^{\circ}$ angle, DU3520 Diatome $2 \mathrm{~mm}$ ) and ultramicrotome

151 (UC6, Leica microsystems, Germany)

15214.200 and 300 mesh copper grids (G200-Cu and G300-Cu, Electron Microscopy Sciences)

153 15.Flat embedding molds for TEM (70900 silicone clear Electron Microcopy Sciences or 70907

154 Dykstra blue, Electron Microscopy Sciences) (Note 13)

155 16. HT7700 transmission electron microscope (Hitachi, Japan) equipped with an8 million pixels

156 format CCD camera driven by the image capture engine software AMT version 6.02.

157 


\section{Methods}

159

160

161

162

\subsection{Observation of biofilms grown on paraffin by CLSM}

\subsubsection{Pre-culture of bacteria}

1.Inoculate $100 \mu \mathrm{L}$ of a glycerol stock of bacteria (strain SP17 or NapRu1) stored at $-80{ }^{\circ} \mathrm{C}$ into $10 \mathrm{~mL}$ of SSW supplemented with $20 \mathrm{mmol} \cdot \mathrm{L}^{-1}$ sodium lactate as a carbon source in a $50 \mathrm{~mL}$ tubeand incubate overnight at $180 \mathrm{rpm}, 30^{\circ} \mathrm{C}$.

2.Transfer $100 \mu \mathrm{L}$ of the culture in $10 \mathrm{~mL}$ of SSW plus $20 \mathrm{mmol} . \mathrm{L}^{-1}$ sodium lactate andincubate overnight at $180 \mathrm{rpm}, 30{ }^{\circ} \mathrm{C}$.

3.Centrifuge the overnight culture at $20{ }^{\circ} \mathrm{C}, 10000 \mathrm{~g}$ for $15 \mathrm{~min}$, wash the cell pellet twice in SSW and resuspend the cells in SSW at an $\mathrm{OD}_{600 \mathrm{~nm}}=0.01$.

\subsubsection{Biofilm culture}

1. Prepare the substratum

Melt the paraffin at $65{ }^{\circ} \mathrm{C}$ and pour it into cassettes for microtome. Let the paraffin cooled-down on a cool top board to allow solidification. Cut the solid paraffin with a microtome in $15 \mu \mathrm{m}$ thick strips. Strips must be transported on ice (for example in a Petri dish) then stored at $4{ }^{\circ} \mathrm{C}$ until use.A thin strip of paraffin is placed on a microscopeglass slide within a Petri dish $(90 \mathrm{~mm})$ or directly on the bottom of a Petri dish $(55 \mathrm{~mm})$. Put the Petri dish in an incubator at $45{ }^{\circ} \mathrm{C}$ for $10 \mathrm{~min}$ to soften the paraffin and make it adhere to the solid support. Before use, decontaminate by exposing the Petri dishtoUV lightfor 5 min.

\section{Inoculate the solid support}

Pour $30 \mathrm{~mL}$ of the bacterial suspension $\left(\mathrm{OD}_{600 \mathrm{~nm}}=0.01\right)$ in the Petri dish $(90 \mathrm{~mm})$ containing the thin paraffin stripstuck on a microscopic slide or $5 \mathrm{~mL}$ in a Petri dish $(55 \mathrm{~mm})$ containing the thin paraffin 
strip stuck on the bottom. Make sure thatthe bacterial suspension covers the whole surface of the solid substratum.Incubate at $30^{\circ} \mathrm{C}$ without shaking for 5 days (Note 14).

\subsubsection{CLSM observation of the biofilm}

\section{Biofilm staining with fluorescent markers (Note 15)}

Remove the culture medium leaving about $1 \mathrm{~mL}$ to keep the biofilm wet. It is important to avoid dehydration to conserve the biofilm structure. Add the selected fluorescent makers to the recommended concentration (see manufacturer's instructions) and incubate at room temperature in dark for 15 min. Here, either Syto®9 (diluted 1:1000) or the mixture Syto®61 (1:1000)/BODIPY® (final concentration $0.05 \mathrm{mg} \cdot \mathrm{mL}^{-1}$ ) are used.

\section{Biofilm observation}

Biofilms grown on paraffin thin film deposited on the bottom of the petri dish are imaged directly, without mounting, through the bottom of the Petri dish with an inverted microscope. This approach is preferred when biofilms are loosely attached to paraffin and mounting would result in loss in the biofilm integrity. However, if a maximal resolution is desired, the biofilm is grown on paraffin film pasted on a microscope slide. Then the biofilm is mounted between the slide and a coverslip with a silicon spacer to avoid compressing it and observed upside down on the inverted microscope.Biofilms mounted or not are observed with a water immersion HCX APO L, 0.80 NA, W U-V-I, Leica 40 X objective with a working distance of $3.3 \mathrm{~mm}$.Adjust the laser excitation and fluorescence signal recuperation according to the characteristic of the markers (absorption and fluorescence emission maxima Syto®9 482/500 nm, Syto®61 628/645 nm, BODIPY® 493/503 nm). (Figure 1). 


\subsection{Observation of biofilms grown on paraffin by TEM}

207

208

209

210

211

212

213

214

215

216

217

218

219

220

221

222

223

224

225

226

The basic principles and techniques of electron microscopy for biological applications are described elsewhere(18). This protocol is designed to visualize more specifically the spatial distribution in the biofilm of cells containing intracytoplasmic inclusions. In order to visualize the extracellular matrix, bacterial capsules or appendixes, other fixative cocktails and other electron microscopy techniques have to be used $(19,20)$.

3.2.1. Pre-culture of bacteria

See subheading 3.1.1.

\subsubsection{Biofilm culture}

1.Coat the bottom of petri dishes with paraffin by pouring $15 \mathrm{~mL}$ of liquid paraffin heated at $50{ }^{\circ} \mathrm{C}$. Let the paraffin solidify by cooling at room temperature.

2.Twenty milliliters of bacterial suspension prepared as described in 3.1.1 areused to inoculate the paraffin coated Petri dishes. Make sure that the whole surface of the solid paraffin is covered by the cell suspension.Incubate at $30{ }^{\circ} \mathrm{C}$ without shaking for 5 days (Note 14).

\subsubsection{TEM observation of the biofilm}

To prevent dehydration, the samples must be kept immersed in solution during the allprocedure, except for step 3. During the change of solutions, it is therefore recommended to not discard all the solution from the previous step. Addition and removal of solutions must be performed with extreme care to avoid biofilm alteration. Be aware of the toxicity of the compounds used (Note 16).

1.Fix the biofilm 
Remove the culture medium from the petri dish and pour $20 \mathrm{~mL}$ of the fixative solution, incubate at room temperature for $1 \mathrm{~h}$. The cacodylate buffer concentration in fixative solution is $0.15 \mathrm{~mol} . \mathrm{L}^{-1}$ for M. hydrocarbonoclasticusSP17 and 0.10 mol. $\mathrm{L}^{-1}$ for $R$. equi NapRu1. At this stage samples can be stored few months in the fixative solution, at $4^{\circ} \mathrm{C}$. Wash three times during $5 \mathrm{~min}$ with the cacodylate bufferat the corresponding concentration.

2.Post-fix the biofilm

Remove the fixative solution, add $20 \mathrm{~mL}$ of post-fixative solution and incubate at room temperature for $1 \mathrm{~h}$. Wash twice for $10 \mathrm{~min}$ in distillated water. At this stage samples can be stored few days maximum, at $4{ }^{\circ} \mathrm{C}$.

\section{Embed the biofilm in agarose}

Discard the distilled water and quickly embed the fixedbiofilm in $30 \mathrm{~mL}$ of a $2.5 \%$ agarose solution maintained above its gelling point at $50{ }^{\circ} \mathrm{C}$ (Note 9). Tilt the Petri dish and carefully swirl the melted agarose to obtain a homogenous surface. Let the agarose gellify for $1 \mathrm{~h}$ at $4{ }^{\circ} \mathrm{C}$.

Detach the agarose gel from the petri dish wall by moving all around the edges of the dish a thin blade inserted between the agarose and the dish wall. Unmold carefully the agarose by detachingit from the paraffin. The biofilm normally separates easily from the paraffin staying in the agarose layer.

Checkvisually that all the biofilm has been removed from the surface of the paraffin.Transfer the agarose slab, biofilm facing down, in a Petri dish containing the first solution of dehydration (30\% ethanol). Make sure that the biofilm bearing face is always immersed in the solution. Cut the agarose slab into big pieces $\left(1 \mathrm{~cm}^{3}\right)$ with a scalpel and choose pieces where the biofilm seems thicker and homogeneous. 
4.Dehydrate the agarose pieces in ethanol solutions series: $50 \%, 70 \%, 90 \%$ and $2 \times 100 \% \mathrm{v} / \mathrm{v}, 15 \mathrm{~min}$ for each step at room temperature. Removal and addition of ethanol solution must be carried out with care to not damage the biofilm. Dehydration procedure can be stopped at the stage of $70 \%$ ethanol. Samples are stable for few days maximum, at $4^{\circ} \mathrm{C}$.

After dehydration reduce the thickness of the agarose layer above the biofilm to $1 \mathrm{~mm}$ and cut small pieces of $3 \mathrm{~mm}$ long by $1 \mathrm{~mm}$ wide. Transfer each piece in an Eppendorf ${ }^{\mathrm{TM}}$ microcentrifuge tube containing $700 \mu \mathrm{L}$ of a $100 \%$ ethanol (third bath).

5. Impregnate successively the dehydrated samples with epoxy resin solutions in ethanol of increasing concentrations: $25 \%$ and $33 \%$ for $10 \mathrm{~min}, 50 \%$ overnight, then $66 \%$ and $75 \%$ for $10 \mathrm{~min}$. Impregnations are performed at room temperature under rotary shaking (Notes 17and 18).Then impregnate with pure (100\%) fresh resin, for $10 \mathrm{~min}$ up to few hours, with the caps of the microcentrifuge tubes opened to let evaporate the last traces of ethanol. Impregnate once more with pure fresh resin overnighton rotary shaking.Finally, impregnate with pure fresh resin with the caps of the microcentrifuge tubes opened inunder vacuum to maximize resin penetration (from $10 \mathrm{~min}$ to few hours). After dehydration and impregnation the biofilm bearing face of agarose pieces can be easily recognized by their black coloration.

6.Include samples in epoxy resin.

Pour a thin layer of pure fresh epoxy resin into TEM moldsand allow to polymerize for 2 hat $60{ }^{\circ} \mathrm{C}$.

Place each impregnated sample, in a mold, on the top of the polymerized epoxy layer in such a way that the biofilm black layer is below and parallel to the bottom of mold. The viscous thin layer of resin in the bottom of the mold will help to stabilize the sample during polymerization (Note 19).

Fill completely the cavity with pure fresh epoxy resin, considering volume reduction during polymerization. Put the mold under vacuum for $10 \mathrm{~min}$ up to few hours to maximize resin penetration 
276 and eliminate air bubbles.Polymerize at $60{ }^{\circ} \mathrm{C}$, during 16 to $18 \mathrm{~h}$, depending on the resin hardness

277 preferred for the cutting. Resin blocks can be stored ad vitam aternam in a temperate and dry place.

279 7.Make ultrathin sections (60 to $80 \mathrm{~nm}$ ) with a diamond knife and an ultramicrotome. Deposit on 200

280 or 300 mesh copper grids (Note 20). Stain each grid with onedrop of $0.05 \%$ OTE solution for 30 min,

281 washed with 4 successive drops of distilled water and dried on Whatman grade $\mathrm{n}^{\circ} 1$ cellulose filter

282 paper.

283

284 8.Observe in a TEM microscope between 80 to $120 \mathrm{kV}$ (Figure 2). Contrast increases when

285 accelerating voltage is decreased and objective aperture is more closed (21). 


\section{Notes}

288

289

290

291

Note 1. Although this method was originally developed for M. hydrocarbonaclasticus SP17 and $R$. equi NapRu1, it can be adapted, by using the appropriated culture medium, to any strain that is able to form biofilm on paraffin or other HOCs, hydrocarbon or lipidsthat are solid at the growth temperature. The HOC must be soft enough to be cut in very thin slices. Crystalized compounds (such as pure alkanes or aromatics) are not suitable since they are not sliceable.

Note 2. Any other medium that allows the studied strain to grow, adhere and form biofilm on HOCcan be employed.

Note 3. Classical Petri dishes are employed. Other diameters can be used. If the biofilm is observed directly through the bottom of the dish, specific Petri dishes with a bottom designed for high-end microscopic analyses have to be used ( $\mu$-Dish50 mm, low, Ibidi) for higher resolution imaging.

Note 4. Microscopic slides and coverslips are cleaned by acetone/ethanol (50/50 V/V), dried and stored in sterile conditions in Petri dishes until used.

Note 5. Syto®9 (green fluorescent dye) and Syto®61 (red fluorescent dye) are nucleic acid stains and nonpolar BODIPY® (green fluorescent dye) labels neutral and non-polar lipid components. Other fluorescent dyes can be used according to the structures to be observed as previously described (22).

Note 6. The use of an inverted CLSM is required to observe directly biofilms in situ without perturbing their architecture during staining and mounting.

Note 7. Various softwares can be used as previously described (22).

Note 8. Adapt and control the osmolarity of the buffer for each type of sample.

Note 9. The agarose solution is maintained at the liquid state at a temperature above its gel point but not too high to avoid the paraffin from melting or any damage to the biofilm.

Note 10. This resin is prepared accordingly to the manufacturer's instructions, aliquotedand stored at $20^{\circ} \mathrm{C}$. 
Note 11. OTE is a non-hazardous reagent used instead of the hazardous uranyl acetate(23).

312

313

314

Note 12. Smaller microcentrifuge tubes are not suitable for dehydration and next steps.

Note 13. Pay attention to the compatibility between the type of resin and the mold materials.

Note 14. Time and temperature depend on the strain cultivated and on the conditions studied. If incubation is very long, prevent the evaporation by humidifying the atmosphere.

Note 15. Wear a lab coat and gloves to manipulate fluorescent markers. Use specific disposal bins. Read the material safety data sheet (MSDS) of the products.

Note 16. Work under a fume hood wearing lab coat, gloves and glasses. Use specific disposal bins. Read the MSDS of the products before use.

Note 17. While facilitating the early stages of impregnation, propylene oxide traditionally employed is not used in this protocol. It is a hazardous product (boiling point at $34^{\circ} \mathrm{C}$ ) that reacts with many plastics. Instead, ethanol is used for mixed baths with epoxy resin although they mix less easily.

Note 18. Number and length of the impregnation steps are adjusted to our models and our epoxy resin. They can be adapted in case of troubles during the sample cutting (block too soft to an ultrathin cut, dissolution of the ultrathin section in the water tank of the knife) or during TEM observations (holes visible in the ultrathin section). Other standardized protocols describing impregnation steps with other resins can be found (24).

Note 19. When placing the samples into the cavities of the molds, it is possible to reference them by adding a small paper with a printed code (pen ink diffuses in the resin) on the opposite side of the sample.

Note 20. Use the lowest possible mesh copper grids to maximize the observation area (i.e. 200 mesh copper grids). Use 300 mesh copper grids for unstable sections under electron beam. 
335

336

337

338

339

340

341

342

343

344

345

346

347

348

349

350

351

352

353

354

355

356

357

We thank the MIMA2 platform (www.jouy.inra.fr/mima2) for its expertise and access to microscopy equipments.

\section{References}

1.Klein B, Grossi V, Bouriat P, Goulas P, Grimaud R (2008) Cytoplasmic wax ester accumulation during biofilm-driven substrate assimilation at the alkane-water interface by Marinobacter hydrocarbonoclasticus SP17. Res Microbiol 159(2):137-144

2. Tanaka D, Takashima M, Mizuta A, Tanaka S, Sakatoku A, Nishikawa A, Osawa T, Noguchi M, Aizawa SI, Nakamura S 2010 Acinetobacter sp. Ud-4 efficiently degrades both edible and mineral oils: isolation and characterization. Curr Microbiol 60:203-209

3.Bouchez-Naïtali M, Rakatozafy H, Marchal R, Leveau JY, Vandecasteele JP (1999)Diversity of bacterial strains degrading hexadecane in relation to the mode of substrate uptake.J Appl Microbiol86(3):421-428

4.Grimaud R (2010) Biofilm development at interfaces between hydrophobic organic compounds and water. In: Timmis KN, McGenity T, de Lorenzo V, van der Meer JR (eds) Handbook of hydrocarbons and lipid microbiology. Springer, Berlin, pp 1491-1499

5.Mounier J, Camus A, Mitteau I, Vaysse PJ, Goulas P, Grimaud R, Sivadon P(2014) The marine bacterium Marinobacter hydrocarbonoclasticus SP17 degrades a wide range of lipids and hydrocarbons through the formation of oleolytic biofilms with distinct gene expression profiles. FEMS Microbiol Ecol 90:816-831

6. Harms H, Smith KEC, Wick LY (2010) Introduction: problems of hydrophobicity / bioavailability. In: Timmis KN, McGenity T, de Lorenzo V, van der Meer JR (eds) Handbook of hydrocarbons and lipid microbiology. Springer, Berlin, pp 1437-1450 
7.Heipieper HJ, Cornelissen S, Pepi M (2010) Surface properties and cellular energetics of bacteria in response to the presence of hydrocarbons. In: Timmis KN, McGenity T, de Lorenzo V, van der Meer JR (eds) Handbook of hydrocarbons and lipid microbiology. Springer, Berlin, pp 1615-1624

8.Whyte LG, Slagman SJ,Pietrantonio F, Bourbonnière L, Koval SF, Lawrence JR, Inniss WE, Greer CW 1999 Physiological adaptations involved in alkane assimilation at a low temperature by Rhodococcus sp. strain Q15. Appl Environ Microbiol 65:2961-2968

9. Eriksson M, Dalhammar G, Mohn WW (2002) Bacterial growth and biofilm production on pyrene. FEMS Microbiol Ecol 40:21-27

10. Wick LY, De Munain AR, Springael D, Harms H (2002) Responses of Mycobacterium sp. LB501T to the low bioavailability of solid anthracene. Appl Microbiol Biotechnol 58:378-385

11. Rodrigues AC, Brito AG, Wuertz S, Melo LF (2005) Fluorene and phenanthrene uptake by Pseudomonas putida ATCC 17514: Kinetics and physiological aspects. Biotechnol Bioeng $90: 281-289$

12. Macedo AJ, Kuhlicke U, Neu TR, Timmis KN, Abraham WR (2005) Three stages of a biofilm community developing at the liquid-liquid interface between polychlorinated biphenyls and water. Appl Environ Microbiol 71:7301-7309

13.Wouters K, Maes E, Spitz JA, Roeffaers MBJ, Wattiau P, Hofkens J, Springael DA (2010) A noninvasive fluorescent staining procedure allows Confocal Laser Scanning Microscopy based imaging of Mycobacterium in multispecies biofilms colonizing and degrading polycyclic aromatic hydrocarbons. J Microbiol Meth 83:317-325

14. Manilla-Perez E, Reers C, Baumgart M, Hetzler S, Reichelt R, Malkus U, Kalscheuer R, Waltermann M, Steinbuchel A (2010) Analysis of lipid export in hydrocarbonoclastic bacteria of the Genus Alcanivorax: Identification of lipid export-negative mutants of Alcanivorax borkumensis SK2 and Alcanivorax jadensis T9. J Bacteriol 192:643-656 
15.Vaysse PJ, Sivadon P, Goulas P, Grimaud R 2011 Cells dispersed from Marinobacter hydrocarbonoclasticus SP17 biofilm exhibit a specific protein profile associated with a higher ability to reinitiate biofilm development at the hexadecane-water interface. Environ Microbiol 13:737-746.

16.Kalscheuer R, Stöveken T, Malkus U, Reichelt R, Golyshin PN, Sabirova JS, Ferrer M, Timmis KN, Steinbüchel A (2007) Analysis of storage lipid accumulation in Alcanivorax borkumensis: Evidence for alternative triacylglycerol biosynthesis routes in bacteria. J Bacteriol 189(3):918-928

17. Gauthier MJ, Lafay B, Christen R, Fernandez L, Acquaviva M, Bonin P, Bertrand JC (1992) Marinobacter hydrocarbonoclasticus gen. nov., sp. nov., a new, extremely halotolerant, hydrocarbondegrading marine bacterium. Int J Syst Bacteriol 42:568-76.

18.Hayat MA (2000) Principles and Techniques of Electron Microscopy - Biological Applications. Cambridge University Press, Cambridge.

19.Erlandsen SL, Kristich CJ, Dunny GM, Wells CL (2004) High-resolution visualization of the microbial glycocalyx with low-voltage scanning electron microscopy: dependence on cationic dyes. J Histochem Cytochem 52:1427-1435

20.Hammerschmidt S, Wolff S, Hocke A, Rosseau S, Müller E, Rohde M (2005) Illustration of pneumococcal polysaccharide capsule during adherence and invasion of epithelial cells. Infect Immun 73(8):4653-4667

21. Dykstra MJ, Reuss LE (2003) Biological electron microscopy: theory, techniques, and troubleshooting, $2^{\text {nd }}$ edition. Kluwer Academic/Plenum Publishers, New York

22.Bridier A, Dubois-Brissonnet F, Briandet R (2014) Methods for biofilms constituents and turnover, Section 1. Destructive and nondestructive methods. In: Dobretsov S, Thomason JC, Williams DN (eds) Biofouling Methods. John Wiley \& Sons, Ltd, Oxford, UK, pp 139-152

23Carpentier A, Abreu S, Trichet M, Satiat-Jeunemaitre BJ (2012) Microwaves and tea: new tools to process plant tissue for transmission electron microscopy. Microsc247(1):94-105 
406 24.Graham L, Orenstein JM (2007) Processing tissue and cells for transmission electron microscopy in 407 diagnostic pathology and research. Nat Protoc2(10):2439-2450

408 


\section{Figure legends}

410

411

412

413

414

415

416

417

Figure 1.Observation of paraffin-grown biofilms by CLSM

Biofilm of M. hydrocarbonaclasticus SP17 (A) and of $R$. equiNapRu1 (C) stained by Syto®9 observed directly through the bottom of a plastic Petri dish and paraffin (optical lens x 40, numerical zoom 1, bar $=50 \mu \mathrm{m}$ ). Biofilm of M. hydrocarbonaclasticus SP17 (B) and of R. equi NapRu1 (D) stained by the mixture BODIPY®/Syto®61 observed upside down through a microscopic cover slip. (optical lens x 40, numerical zoom 4, bar $=10 \mu \mathrm{m}$ ). Intracytoplasmic lipids are abundant during growth ofM. hydrocarbonaclasticus SP17 on paraffin (green staining in B) but not for R. equiNapRu1 (D).

Images in A andC are three-dimensional projections of biofilm structures reconstructed using the Easy 3D function (in blend mode) of the IMARIS 7.7.2 software. B and Dare xy-images for which the overlay of the two channels and the scale bar were performed using Fiji software.

Figure 2.TEM observation of M. hydrocarbonoclasticus SP17 (A) and R. equiNapRu1 (B).

Only the bottom of the R. equi NapRu1 biofilm (i.e. the side in contact with paraffin during growth) is shown as the biofilm is very thickwith no stratification within the ultrastructure of cells. The $R$. equi NapRu1biofilm (Fig. 2B) contain few cells, as compared with the M. hydrocarbonoclasticusSP17 biofilm (Fig. 2A), and probably a lot of extracellular matrix. Numbers of cells of $M$. hydrocarbonoclasticusSP17 contained big inclusions in contrast to R. equi NapRu1cells. These observations are in agreement withCLSM imaging (Fig. 1B, D). 